\title{
NEW ELECTROMAGNETIC FORCE SENSOR: MEASURING THE DENSITY OF LIQUIDS
}

\author{
Z. Abbassi ${ }^{1}$, A. Benabdellah ${ }^{2}$, A. Nakheli ${ }^{3}$ \\ ${ }^{I}$ Moulay Ismail University, F.S, Laboratory LASMAR, Meknes, Morocco \\ ${ }^{2}$ Moulay Ismail University, F.S, Laboratory LASMAR, Meknes, Morocco \\ ${ }^{3}$ Moulay Ismail University, ESTM BP 3103 Toulal, Meknes, Morocco
}

\begin{abstract}
We realized an electromagnetic force sensor for measuring the density of liquids by hydrostatic force exerted by liquids on a diver reference which characteristics are precisely known. The accuracy of the sensor is $\Delta m=0.3 \mathrm{mg}$ and referring to the force is $\Delta F=$ $3 \mu N$.We will present in this paper the results of measuring the density of water-ethanol systems which was obtained by the accuracy of $\Delta \rho=10^{-4} \mathrm{~g} / \mathrm{cm}^{3}$. The operating principle of this sensor is based on the fundamental laws of electromagnetism (Faraday-Lenz law). The density changes as a function of the molar fraction are monotonous in accordance with theory and the values of density measured with this device are in good agreement with the results found in the bibliography.
\end{abstract}

Keywords: Electromagnetic force sensor, accuracy, density.

\section{INTRODUCTION}

Microelectronics is a key factor in the scientific and technical progress via the computer. However, this tool cannot function by itself, it is necessary to provide data, that is to say the results of relevant and reliable measurements. Thereby we cannot move forward or be developed unless we are able to accurately measure the various physical quantities required in depth knowledge and / or greater control of industrial processes.

In this context, improving the characteristics of the sensor, which is the basic element of data acquisition systems, has become an imperative need. In fact, the reliability of the results found after data processing depend directly on the accuracy and the reliability of the sensor.

Density is a physical measure whose knowledge is essential to assess the average intermolecular distance. These thermal variations are related to various thermodynamic parameters and to the solid texture. Taking for example the expansion coefficient which is sensitive to the concentration of defects (vacancies, interstitials, dislocations) to doping, and also to the porosity and nature of the grains. Dilatometry is an investigation means used extensively in the phase transitions study that are either first order or second order. Previous measurements of density depending on the temperature by buoyant forces were carried out on aqueous solutions of propanediol1,2 such as the Glycerol, Maltitol, Sorbitol and Glucose in the liquid state and a glassy state, in order to examine viscosity changes as a function of the average intermolecular distance [1-9].

The design of the force electromagnetic sensor enters in this context to complete with measuring the viscosity and the average intermolecular distance of liquids, especially for high-viscosity in the liquid and the glassy state. The existing force sensors are generally electrodynamics, piezoelectric or using strain gauges $[\mathbf{1 0}, \mathbf{1 1}, \mathbf{1 2}]$. The operating principle of the sensor that we propose is based on the fundamental laws of electromagnetism and the mechanical properties of elasticity of a spring.

\section{ELECTROMAGNETIC FORCE SENSOR}

\subsection{Description}

Our goal is to design and produce a force sensor with an important extensive measurement and accuracy for many applications (measurements of density, viscosity and surface tension). The operating principle of the proposed sensor is based on the fundamental laws of electromagnetism, which justifies its name "Electromagnetic force sensor."

This sensor consists of two flat circular coils of a diameter of $2 \mathrm{~cm}$ and 30 coil turns made by a copper conductor wire of a section of $0,06 \mathrm{~mm}$, placed in parallel. One of the flat coils (Fixed Coil) is fixed on an insulating horizontal support and the other flat coil (Moving Coil) is wound on an insulating cylinder of $2 \mathrm{~cm}$ in diameter, the lower end passes through the free surface formed by the coil fixed, and the upper end is connected to a spring which is itself attached to a fixed support. At the lower end of the cylinder that acts as a guide, we set a hook for hanging masses.

The entire system formed (fixed flat coil, guide roller, spring and moving flat coil) is aligned on the same vertical axis (Fig -1). 


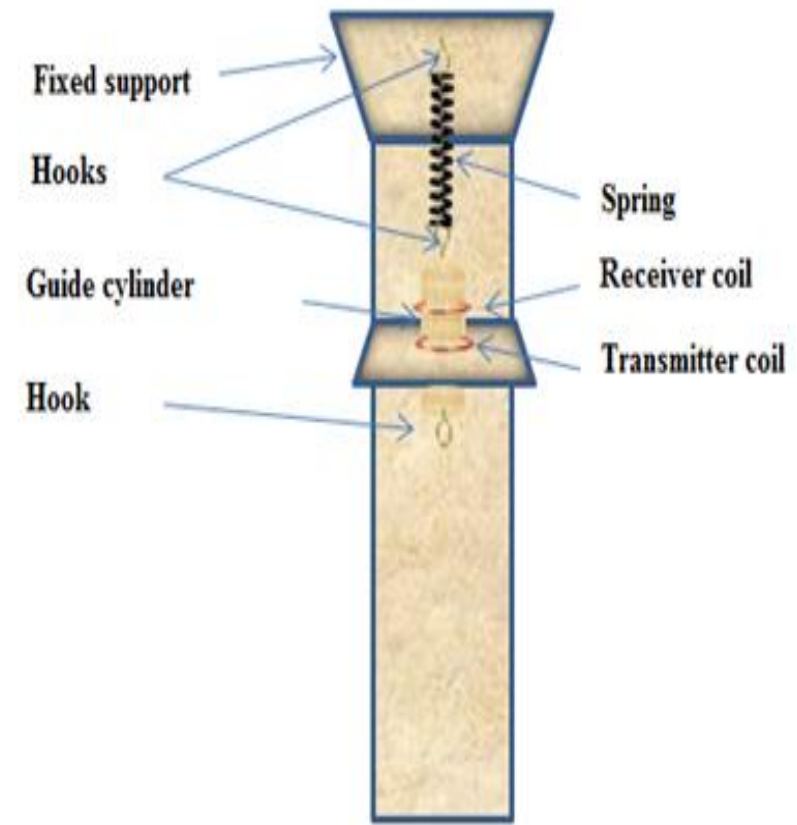

Fig -1: Electromagnetic force sensor

The cylinder is movable vertically upwards or downwards virtually without friction, when we exert a force on its lower end, which has the effect of extending or compressing the spring, it bring closer or away the guide cylinder (moving coil) from the fixed coil.

The fixed coil is supplied by an low frequency generator of a frequency $\mathrm{fO}=16 \mathrm{KHz}$ whose phase conditions and amplification are satisfied; therefore, it is traversed by a sinusoidal current which creates a sinusoidal magnetic flux density along its axis, the latter creates through the moving coil a variable flow $\Phi$ and induced sinusoidal electromotive force measurable, the maximum value of the EMF induced depends on the distance $\mathrm{x}$ between the two coils, the flux $\Phi$ is proportional to the magnetic induction $B$ that changes as a function of $\mathrm{x}$ are given by the following relation:

$$
B(x)=\frac{\mu_{0} I R^{2}}{2 \sqrt{\left(R^{2}+x^{2}\right)^{3}}}
$$

With I: The maximum amplitude of the current flowing through the coil, $\mathrm{R}$ is the coil radius and $\mathrm{x}$ is the distance between the two coils.

The magnetic field created by the transmitter coil is at a maximum at the center of the coil $(\mathrm{x}=0)$ :

$$
B_{0}=\frac{\mu_{0} I}{2 R}
$$

The second flat moving coil is the receiver coil; it acts as an inductive sensor which converts a magnetic field passing therethrough to a voltage. This receiver coil at a distance $\mathrm{x}$ from the fixed flat coil will receive an electromotive force whose expression is given by the Lenz-Faraday law e = $\mathrm{d} \Phi / \mathrm{dt}$. The magnetic flux $\Phi$ through the receiver coil is proportional to the magnetic induction $\mathrm{B}$ whose variations in terms of $\mathrm{x}$ are given by the relation (1), and therefore the induced electromotive force will have similar variations in function of $x$ in a given frequency. The maximum amplitude of this induced voltage will be greater as the frequency is higher. Thus, we realized an electromagnetic displacement sensor, at each position $\mathrm{x}$ of the receiver coil corresponds a determined induced voltage, this voltage takes its maximum value when the two coils are juxtaposed and decreases as the receiver coil moves away from the transmitter coil. The use of the spring, which acts as a force-displacement converter, has allowed us to use the sensor as a force sensor.

When a mass suspended on the hook on the bottom of the cylinder, this latter moves down by extending the spring, and the distance $\mathrm{x}$ between the two coils is reduced and as a result the voltage induced across the receiver moving coil increases. The induced voltage is sinusoidal and its amplitude is low, so it has been necessary to introduce circuits for amplification, rectification and filtering to make this voltage usable, the corresponding sensor output signal conditioning circuit is as follows: 


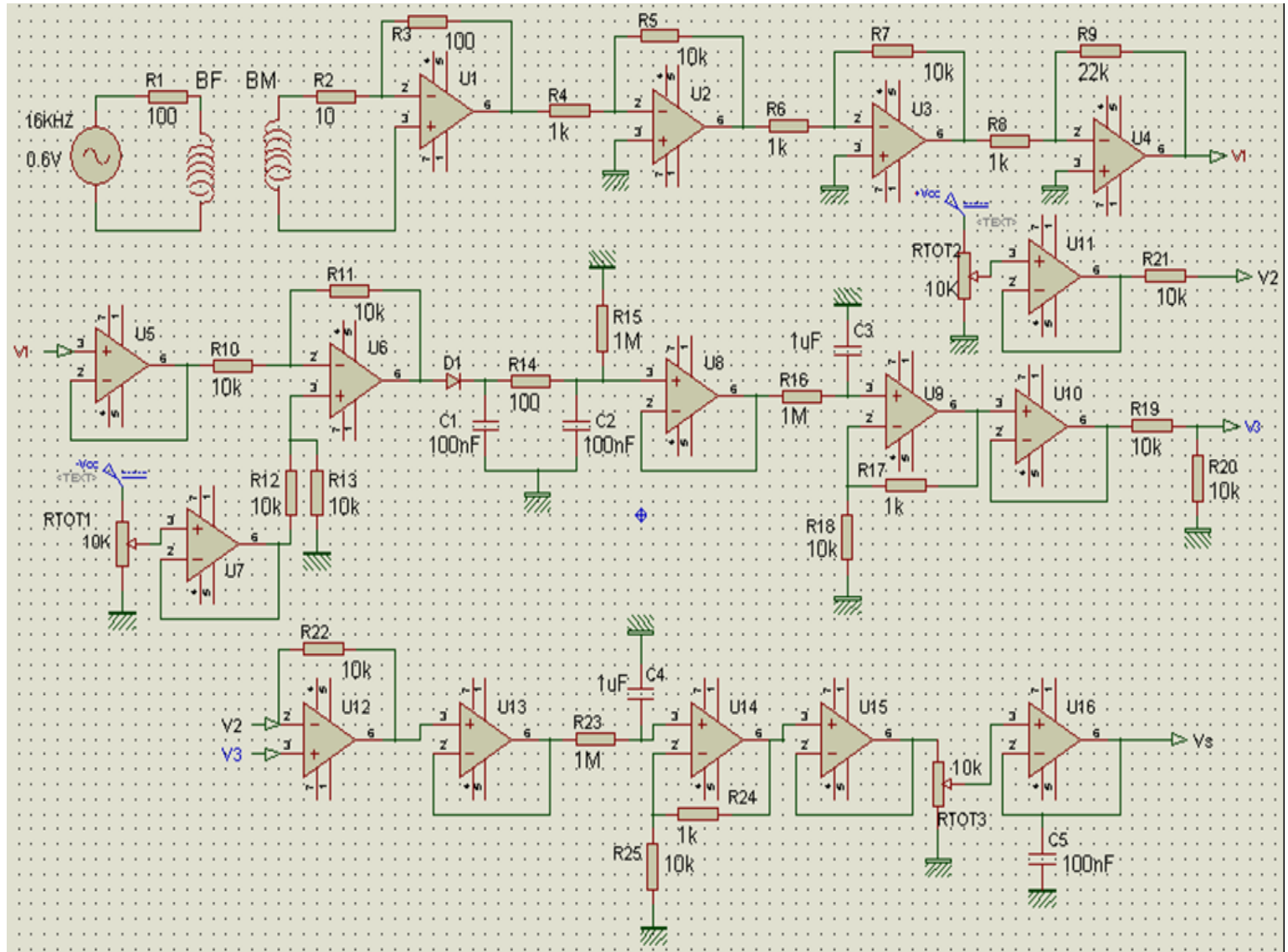

Fig -2: Conditioning circuit

Amplifiers used are LM324 which are power supplied from a $\pm 15 \mathrm{~V}$ symmetrical stabilized source

\subsection{Characteristics of the Electromagnetic Sensor}

\subsubsection{Sensor Drift}

When we turn the sensor on, the output voltage decreases exponentially and after 10 to 15 minutes of operation, this voltage stabilizes at a characteristic constant of the experimental device that can be canceled with a suitable circuit for zero adjustment.

\subsubsection{Sensitivity}

The sensitivity of the sensor depends on the spring constant and the conditioning circuit (particularly the gain of the amplifier stages), we achieved a sensitivity of $3 \mathrm{mg} / \mathrm{mV}$ at the beginning (before suspending masses). However, the electromagnetic unit consisting of transmitter and receiver coil may be modified to increase the sensor sensitivity. In general, inductive sensors were first used for historical reasons, but are still interesting because of their accuracy and robustness. In addition, the coils are cheap and easy to produce industrially, at least within reasonable dimensions. The induction of a coil is directly related to its turns number, its diameter and thus its size; the small coils generally have a lower sensitivity. However, advanced techniques now allow the production of coils of small size with high sensitivity, with complex shapes or a larger number of turns.
The frequency domain for an inductive sensor depends strongly of its impedance.

\subsubsection{Measuring Range}

From $0 \mathrm{~g}$ to $1,2 \mathrm{~g}$, it's related to the mechanical properties of the spring. The sensor is designed to work in a range of 0 to $1,2 \mathrm{~g}$.

\subsubsection{Accuracy}

The sensor accuracy depends on the specific elements of the experimental device (coils, cylinder, friction, distance between coils, spring, and the signal conditioning circuit), and on the quality of the measuring instruments used. In our case we used a digital multimeter whose accuracy is $0.1 \mathrm{mV}$. The voltages delivered by the sensor are measured with an error of $0,5 \mathrm{mV}$, and the accuracy of the measured masses is estimated to $\Delta \mathrm{m}=0.3 \mathrm{mg}$ at the origin. So we can say that all measure masses between 0 and $1.2 \mathrm{~g}, \Delta \mathrm{m}$ is equal or less than $\Delta \mathrm{m}=0.3 \mathrm{mg}$. This is related to the sensor sensitivity wich is variable and depends on the distance between coils, this sensitivity changes from $3 \mathrm{mg} / \mathrm{mV}$ to $2 \mathrm{mg} / \mathrm{mV}$, so 0,2 $\mathrm{mg} \leq \Delta \mathrm{m} \leq 0,3 \mathrm{mg}$.

\subsubsection{Hysteresis}

We have made measurement on the sensor by hooking increasingly masses from $0 \mathrm{~g}$ to $1,2 \mathrm{~g}$ in steps of $100 \mathrm{mg}$, and then we note the output voltage values by removing masses 
from $1,2 \mathrm{~g}$ to $0 \mathrm{~g}$ in steps of $100 \mathrm{mg}$. The results are perfectly reversible and there was no hysteresis cycle due to the mechanical properties of the spring which acts as a forcedisplacement converter. We were limited to a maximum weight of $1,2 \mathrm{~g}$, and beyond, there is a small deformation appearing. The choice of a good spring (perfectly elastic) is important. The spring constant of the spring used is $\mathrm{k}=2 \mathrm{mN} / \mathrm{mm}$.

\subsection{Sensor response from $0 \mathrm{~g}$ to $1,2 \mathrm{~g}: \mathrm{V}=\mathrm{f}(\mathrm{m})$}

The characteristic curve of the sensor shown in Fig.2 is obtained by hooking high-precision masses from $0 \mathrm{~g}$ to $1,2 \mathrm{~g}$ in steps of $100 \mathrm{mg}$ (Table 1), and we note the voltage values corresponding to each mass. The curve response is not linear, it is rather parabolic in relation with the sensor sensitivity as a function of the distance between coils.

Table -1: Sensor calibration

\begin{tabular}{|l|l|l|l|l|l|l|l|l|l|l|l|l|l|}
\hline $\mathbf{m}(\mathbf{m g})$ & 0 & 100 & 200 & 300 & 400 & 500 & 600 & 700 & 800 & 900 & 1000 & 1100 & 1200 \\
\hline $\mathbf{V}(\mathbf{m V})$ & 130,3 & 153,3 & 177,7 & 204,2 & 232,5 & 263,2 & 296,1 & 331,1 & 369,4 & 410,6 & 454,6 & 502,2 & 553,7 \\
\hline
\end{tabular}

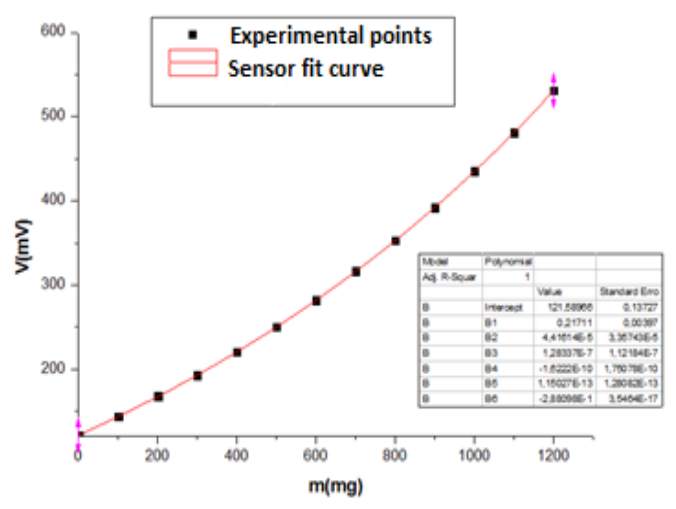

Chart -1: Sensor response from $0 \mathrm{~g}$ to $1,2 \mathrm{~g}: \mathrm{V}=\mathrm{f}(\mathrm{m})$

We used a polynomial fit of order 7 which is characterized by a standard deviation commensurate with the experimental sensor accuracy. The polynomial fit of the mass as a function of the voltage $(m=f(V))$ shown below will be most useful for determining the mass of any unknown by knowing its corresponding voltage delivered by the sensor. The corresponding polynomial adjustment is given by:

$$
m=\sum_{i=0}^{7} a_{i} V^{i}
$$

With $\mathrm{v}$ in $\mathrm{mV}$, and $\mathrm{m}$ in $\mathrm{mg}$

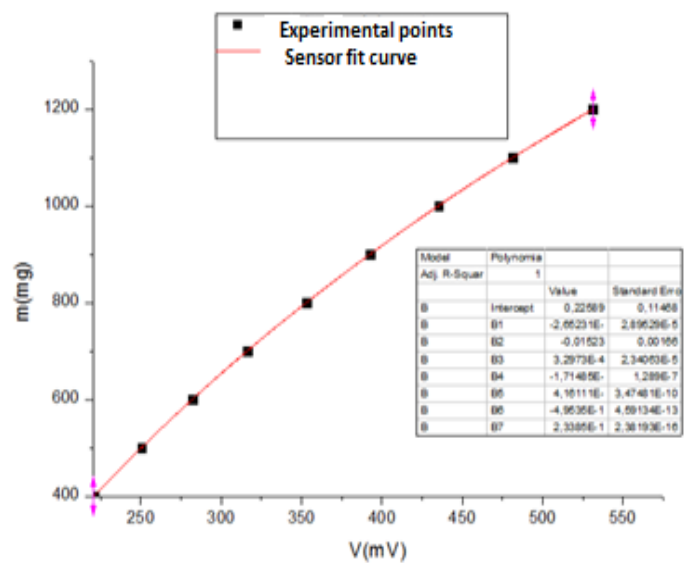

Chart -2: Sensor response from $0 \mathrm{~g}$ to $1,2 \mathrm{~g}$
The polynomial adjustment of the mass as a function of the voltage corresponding to the experimental accuracy of our sensor is as follows:

$$
\begin{gathered}
\mathrm{m}(\mathrm{mg})=\mathrm{A}+\mathrm{B}_{1} \mathrm{~V}+\mathrm{B}_{2} \mathrm{~V}^{2}+\mathrm{B}_{3} \mathrm{~V}^{3}+\mathrm{B}_{4} \mathrm{~V}^{4}+\mathrm{B}_{5} \mathrm{~V}^{5}+\mathrm{B}_{6} \mathrm{~V}^{6} \\
+\mathrm{B}_{7} \mathrm{~V}^{7}
\end{gathered}
$$

With:

$\mathrm{A}=0,22589$;

$\mathrm{B}_{1}=-2,65231.10^{4} \quad ; \mathrm{B}_{2}=-0,01523$

$\mathrm{B}_{3}=3,2973.10^{(-4)} \quad ; \quad \mathrm{B}_{4}=1,71485.10^{(-6)}$

$\mathrm{B}_{5}=4,16111.10^{(-9)} ; \quad \mathrm{B}_{6}=-4,9535.10^{(-12)}$

$\mathrm{B}_{7}=2,3385.10^{(-15)} ; \mathrm{r}^{2}=1 \quad$ et $\sigma=0,23673$

$\mathrm{B}_{\mathrm{i}}$ : Coefficients of the characteristic polynomial.

$r^{2}:$ Correlation coefficient

$\sigma:$ Residual sum of squares

\section{DENSITY OF SYSTEMS $x\left(\mathrm{C}_{2} \mathrm{H}_{6} \mathrm{O}\right),(1-\mathrm{x}) \mathrm{H}_{2} \mathrm{O}$}

\subsection{Preparation of Water-Ethanol Mixtures}

The mixtures were prepared by using absolute ethanol and distilled water.

To analyze in good conditions the influence of the mole fraction on the density, we systematically prepared nine systems whose mole fraction $\mathrm{x}$ is ranged from 0 to 1 with a constant interval $\Delta x=0.1$. By mixing a mass $\mathrm{m} 1$ of a liquid whose molar mass is $\mathrm{M} 1$, and a mass $\mathrm{m} 2$ of a liquid whose molar mass is M2, we get a system of mass $m$ whose weight concentrations are related to the mole fractions by the following relations:

$$
\begin{aligned}
& c_{1}=\frac{m_{1}}{m_{1}+m_{2}}=\frac{1}{1+k\left(\frac{1}{x 1}-1\right)} \\
& c_{2}=\frac{m_{2}}{m_{1}+m_{2}}=\frac{1}{1+k\left(\frac{1}{x 2}-1\right)}
\end{aligned}
$$


The molar masses of ethanol $\left(\mathrm{C}_{2} \mathrm{H}_{6} \mathrm{O}\right)$ and water $\left(\mathrm{H}_{2} \mathrm{O}\right)$ are respectively:

$$
\mathrm{M}_{1}=46 \mathrm{~g} \text { et } \mathrm{M}_{2}=18 \mathrm{~g} \text {. }
$$

And

$$
\mathrm{K}=\frac{M_{2}}{M_{1}}=0.39130 \text {. }
$$

We calculated the weight concentration of ethanol $\mathrm{c}(\mathrm{c}=\mathrm{c} 1)$ for each mole fraction, and the mass $\mathrm{m} 1$ corresponding to get a mixture of standard mass $(\mathrm{m}=100 \mathrm{~g})$. The weights were made by using a Pionner precision balance sensitive to $0,0001 \mathrm{~g}$.

\subsection{Density Measurement}

In classical continuum mechanics, the static of real fluids is identical to that of perfect fluids, as in the absence of flow, viscous forces do not intervene. As a result, the constraint tensor $\sigma$ is an isotropic tensor of the form: $\sigma=-p$ I ( $p$ is the hydrostatic pressure and I is the unit tensor).

This fundamental relation is the origin of Archimedes principle which indicates that the upward buoyant force that is exerted on a body immersed in a fluid whether fully or partially submerged, is equal to the body displaces.

Methods using the Archimedes principle are classical concerning the solids density measurements. they consist on measuring the apparent weight of solids in liquids whose density is accurately known which enable the determination of the solids volumes and densities. This technique has been successfully used for the Propanediol 1.2, Glycerol and Maltitol mixtures [13].

The experimental device that we propose allows the density measurements of liquids and solids in different temperatures.

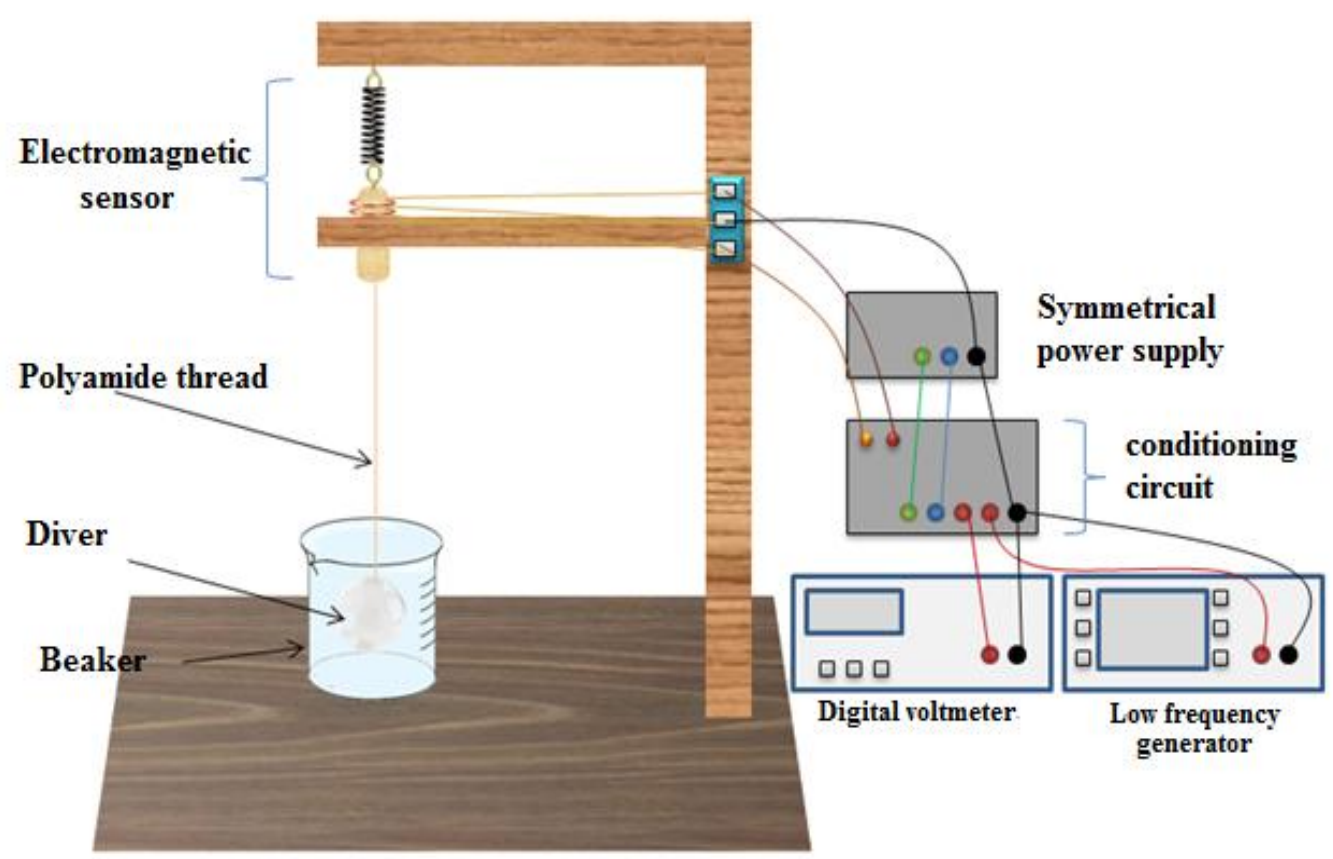

Fig -3: Densimeter

We denote by $\rho_{\mathrm{L}}$ the density of the liquid to study which is expressed in $\mathrm{g} / \mathrm{cm}^{3}, M_{p}$ is the diver mass in gram, $\rho_{p}$ its density $\left(\rho_{p}>\rho_{L}\right)$ and $V_{p}$ its volume in $\mathrm{cm}^{3}$ which is equal to the displaced fluid volume, and $g$ is the gravitational field intensity.

The intensity $\mathrm{P}_{\mathrm{A}}$ of the Archimedes buoyancy and the diver apparent weight $\mathrm{F}$ are given by:

$$
\begin{aligned}
& P_{A}=\rho_{L} V_{p} g=\rho_{L} M_{p} g / \rho_{p} \\
& F=M_{p} g-P_{A}=\left(1-\rho_{L} / \rho_{p}\right) M_{p} g
\end{aligned}
$$

The measurement of $F$ gives directly the value of $\rho_{\mathrm{L}}$ :

$$
\rho_{L}=\rho_{p}\left(1-F / M_{p} g\right)
$$

From a practical point of view, the apparent weight mass was measured by the force sensor described previously, which the measuring range is $1,2 \mathrm{~g}$, which was calibrated by using high-precision masses, results are given in the previous paragraph.

We have made measurements of density of water-ethanol mixtures using a solid diver which the characteristics were experimentally measured. 


\subsubsection{Experimental determination of the Diver} Characteristics

The diver mass was measured by a Pionner precision balance sensitive to $0,1 \mathrm{mg}$.

To determine its volume, we connected the diver to the sensor by using a fine polyamide thread of $0.1 \mathrm{~mm}$ diameter, of $4 \mathrm{~cm}$ length, and whose mass is negligible, and by immersing completely the diver in the distilled water (as a reference liquid) contained in a beaker, the sensor delivers a voltage $\mathrm{V}$ ' which allows to determine the volume from the following equation:

$$
v_{p}=\frac{M_{p}-m^{\prime}}{\rho_{L}}
$$

The apparent mass $\mathrm{m}$ ' of the diver is determined by the adjustment polynomial of the sensor.
Results obtained are summarized in the following table:

Table -2: Experimental characteristics of the diver

\begin{tabular}{|l|l|l|l|l|}
\hline $\begin{array}{l}\mathrm{V}^{\prime} \\
(\mathrm{mV})\end{array}$ & $\begin{array}{l}\mathrm{m}^{\prime} \\
(\mathrm{mg})\end{array}$ & $\mathrm{M}_{\mathrm{p}}(\mathrm{g})$ & $\mathrm{V}_{\mathrm{p}}\left(\mathrm{cm}^{3}\right)$ & $\rho_{\mathrm{p}}\left(\mathrm{g} / \mathrm{cm}^{3}\right)$ \\
\hline 265,8 & 549,6 & 3,3992 & 2,8496 & 1,19285 \\
\hline
\end{tabular}

\subsubsection{Density Measurement of Water-Ethanol}

\section{Systems}

To calculate the density of each solution we use the following equation:

$$
\rho_{\mathrm{L}}=\rho_{\mathrm{P}}-\mathrm{m}^{\prime} / \mathrm{V}_{\mathrm{p}}
$$

The obtained results are summarized in the following table:

Table -3: Summary of results obtained by the diver

\begin{tabular}{|l|l|l|l|l|l|l|l|l|l|l|l|}
\hline $\mathrm{x}$ & 0 & 0,1 & 0,2 & 0,3 & 0,4 & 0,5 & 0,6 & 0,7 & 0,8 & 0,925 & 1 \\
\hline $\mathrm{V}^{\prime}(\mathrm{mv})$ & 265,8 & 307,4 & 344,8 & 380,2 & 407,9 & 431,5 & 450,8 & 468,3 & 483,4 & 501,1 & 509,0 \\
\hline $\mathrm{m}^{\prime}(\mathrm{mg})$ & 549,6 & 675,1 & 778,1 & 869,0 & 936,4 & 991,5 & 1034,6 & 1072,1 & 1103,3 & 1138,7 & 1154,3 \\
\hline$\rho_{\mathrm{L}}\left(\mathrm{g} / \mathrm{cm}^{3}\right)$ & 1 & 0,95593 & 0,91979 & 0,88791 & 0,86423 & 0,84492 & 0,82979 & 0,81663 & 0,80569 & 0,79326 & 0,78778 \\
\hline
\end{tabular}

The variation of the voltage delivered by the force sensor $\mathrm{V}$ ', of the apparent mass $\mathrm{m}$ ' and of the density $\rho_{L}$ as a function of the mole fraction $\mathrm{x}$ are presented in the following figures:

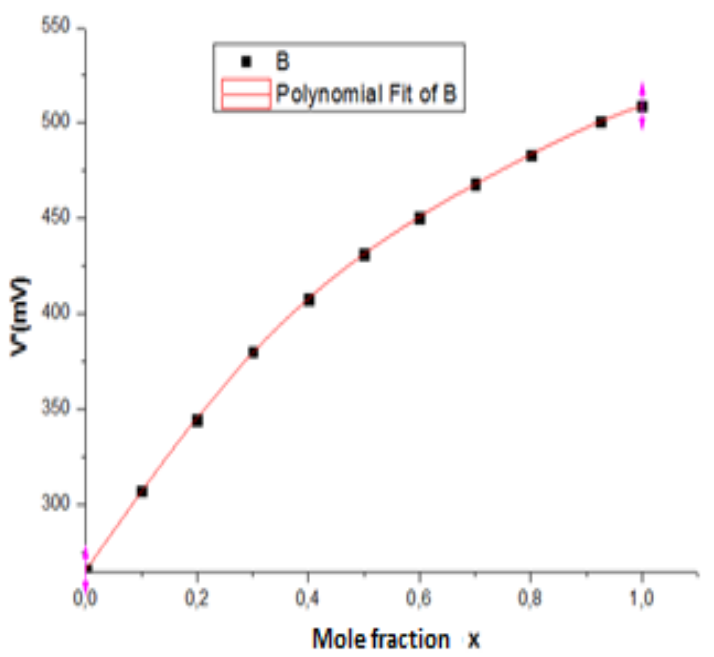

Chart -3.a: $\mathrm{V}^{\prime}=\mathrm{f}(x)$

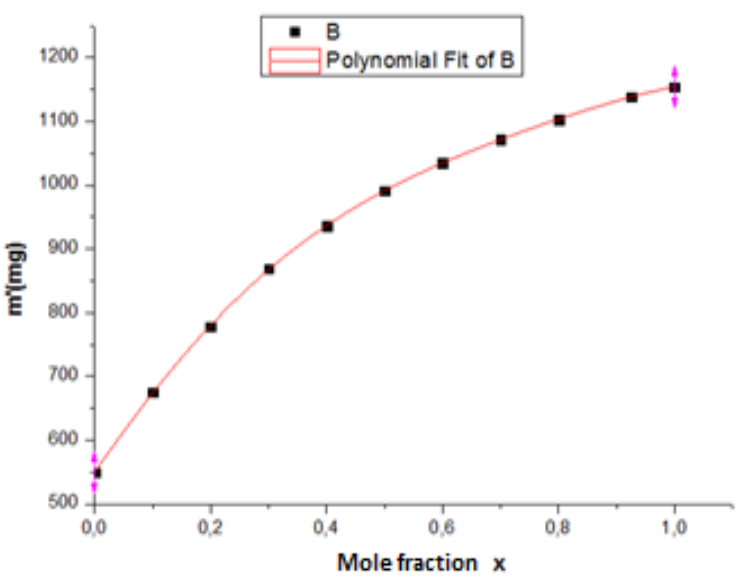

Chart -3.b: $\mathrm{m}^{\prime}=\mathrm{f}(x)$

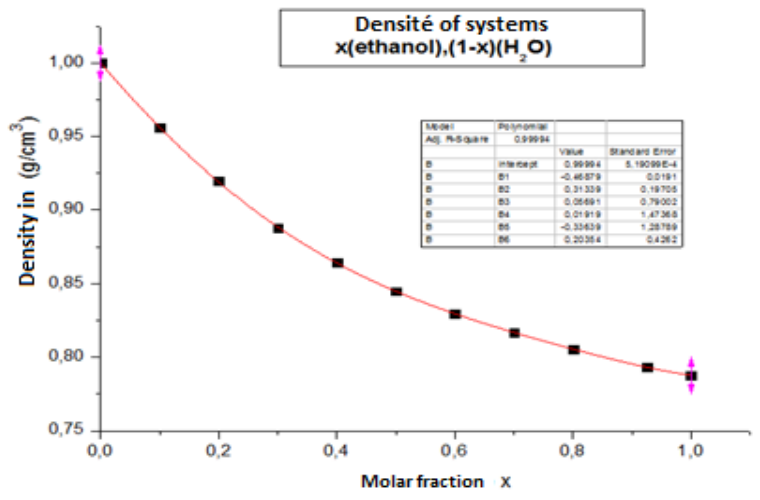

Chart -3.c: $\rho_{\mathrm{L}}=\mathrm{f}(x)$ 


\subsection{Sensitivity of the Experimental Device}

The apparent mass of the diver:

$$
\mathrm{m}^{\prime}=\left(\rho_{\mathrm{p}}-\rho_{\mathrm{L}}\right) \mathrm{V}_{\mathrm{p}}
$$

The variation of the density of the liquid $\Delta \rho_{\mathrm{L}}$ causes a variation $\Delta \mathrm{m}^{\prime}$ as:

$$
\Delta \mathrm{m}^{\prime}=\mathrm{Vp} \Delta \rho_{\mathrm{L}}
$$

As a result, the sensitivity of the equipment is higher as the volume of the diver is important.

Concerning our diver: $\mathrm{V}_{\mathrm{p}} \approx 3 \mathrm{~cm}^{3}$ and assuming

$$
\Delta \mathrm{m}^{\prime}=0,3 \mathrm{mg} \text {, we obtain } \Delta \rho_{\mathrm{L}}=1 \cdot 10^{-4} \mathrm{~g} / \mathrm{cm}^{3}
$$

\subsection{Measurement Accuracy of $\rho_{L}$}

The density is calculated from the measurement of $\mathrm{M}_{\mathrm{p}}, \mathrm{V}_{\mathrm{p}}$, and $\mathrm{m}^{\prime}$ by using the following equation:

$$
\rho_{L}=\frac{M_{p}-m^{\prime}}{v_{p}}
$$

We deduce that the relative error is as follow:

$$
\frac{\Delta \rho_{L}}{\rho_{L}}=\frac{\Delta M_{p}+\Delta m^{\prime}}{\rho_{L} v_{p}}+\frac{\Delta v_{p}}{v_{p}}
$$

It depends on the sensor characteristics and those of the diver. In particular, it is advantageous to use a volume $\mathrm{Vp}$ high enough to reduce this error to an acceptable value.

The mass of the diver has been measured with an accuracy of $0,0001 \mathrm{~g}$ (using a precision balance whose measuring range is $210 \mathrm{~g}), \Delta \mathrm{M}_{\mathrm{p}}=0,1 \mathrm{mg}, \Delta \mathrm{m}^{\prime}=0,3 \mathrm{mg}, \Delta \mathrm{V}_{\mathrm{p}}=0,0004$ $\mathrm{cm}^{3}, \mathrm{~V}_{\mathrm{p}}=2,8496 \mathrm{~cm}^{3}$ and $2,24485 \leq \rho_{\mathrm{L}} \mathrm{V}_{\mathrm{p}} \leq 2,8496$

The application of these values in the equation (15) gives:

$$
\frac{\Delta \rho_{L}}{\rho_{L}}=4.10^{-4} \mathrm{~g} / \mathrm{cm}^{3}
$$

After comparing and presenting in the same graph the density values as well as those found in the bibliography HANDBOOK OF CHEMISTRY AND PHYSICS (density and refractive index) [14], chart $\mathbf{- 4}$. We remarked that the obtained curves are close to the theoretical curves and we get results quite close to the theoretical results expected.

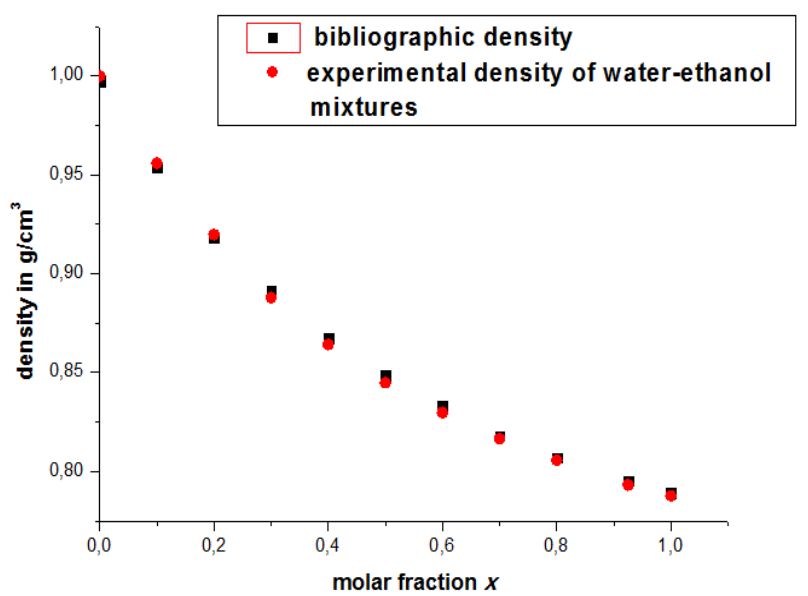

Chart -4: Comparing our density measurements with the bibliography

\section{INTERMOLECULAR DISTANCES}

The intermolecular distances $\mathrm{d}$ to calculate by knowing $\rho(\mathrm{x})$ are an average distances determined by the number of molecules $\mathrm{n}$ contained in a volume $\mathrm{V}$ :

$$
d^{3}=\frac{v}{n}
$$

That represents the average distance between any two molecules from the mixture. This distance can be easily expressed by using the molar mass of the mixtures: $M=x$ $\mathrm{M}_{1}+(1-\mathrm{x}) \mathrm{M}_{2}$, the density $\rho$ and the Avogadro's number $\mathrm{N}$ :

$$
d=\left(\frac{M}{\rho N}\right)^{1 / 3}
$$

We calculated these distances in $\AA$ and we represented their variations as a function of the mole fraction. These variations are monotonous of 4.59 Á for the Ethanol to 3.10 Á for H2O. See Table -5 and Chart -5:

Table -4: Average intermolecular distance depending on the mole fraction $\mathrm{x}$

\begin{tabular}{|l|l|l|l|}
\hline $\mathrm{x}$ & $\mathrm{M}(\mathrm{g})$ & $\rho\left(\mathrm{g} / \mathrm{cm}^{3}\right)$ & $\mathrm{d}(\AA)$ \\
\hline 0 & 18 & 1 & 3,10 \\
\hline 0,1 & 20,8 & 0,95593 & 3,31 \\
\hline 0.2 & 23,6 & 0,91979 & 3,49 \\
\hline 0.3 & 26,4 & 0,88791 & 3,67 \\
\hline 0.4 & 29,2 & 0,86423 & 3,83 \\
\hline 0.5 & 32 & 0,84492 & 3,98 \\
\hline 0.6 & 34,8 & 0,82979 & 4,11 \\
\hline 0.7 & 37,6 & 0,81663 & 4,24 \\
\hline 0.8 & 40,4 & 0,80569 & 4,37 \\
\hline 0.925 & 43,9 & 0,79326 & 4,51 \\
\hline 1 & 46 & 0,78778 & 4,59 \\
\hline
\end{tabular}




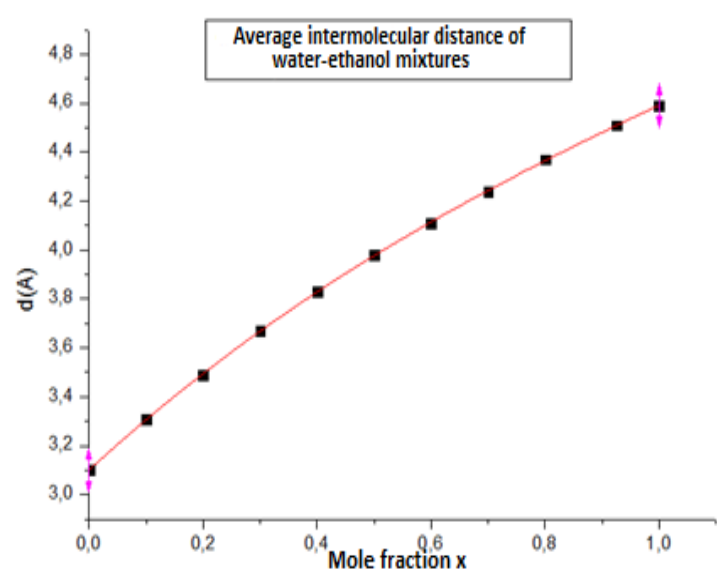

Chart -5: Average intermolecular distance variations as a function of the mole fraction $\mathrm{x}$

\section{CONCLUSIONS}

We realized an electromagnetic force sensor which allows studying the density variations of water-ethanol mixtures as example depending on the mole fraction and estimating the average molecular distance in these mixtures.

The results obtained with our densimeter are in good agreement with the bibliographic results, and the density variations depending on the mole fraction are monotonous [15].

The performances of this electromagnetic sensor can be improved by making a few changes to the oscillation frequency, the amplifying and filtering circuits, and by using a ferromagnetic cylinder to best concentrate the magnetic field lines and increase the sensitivity of the sensor. Another improvement can be imported concerning the reduction of the diameter of the coils, thinking of miniaturization.

Applications of these new generation sensors are numerous, and can be used for manufacture of several measuring instruments and instructional models, as example the manufacture of densimeters (case treated in this paper), dynamometers, viscometers, extensometers, balances, accelerometers, inclinometers, gravimeters, seismometers, thermometers, pressure sensors...etc.

Appropriate technologies for the realization of micro-coils (coils of very small dimensions) will undoubtedly have an important qualitative jump for these sensors.

\section{REFERENCES}

[1]. Miner C.S and Dalton N.N., Glycerol (Reinhold, New York 1953)

[2]. Harran D., Bull. Soc. Chem. Fr 1 (1978) 40-4

[3]. Huck JR., Noyel GA and Jorat LJ., IEEE Trans. Elec.Ins. 23 (1988)627-38

[4]. Claudy PM., CommerçonJC., Letoffe JM., Huck JR., Lotfi N. and Nakheli.A., $1^{\text {st }}$ liquid Matter conf. E.C.A., Vol 14C( Lyon,1990) A31.

[5]. Nakheli.A., Thèse (Lyon 1992).
[6]. Nakheli.A. and Huck .J., Cong. Soc. Franc.Phys., Coll H ( Toulouse , 1993) HP 5

[7]. Nakheli.A., Huck .J. and Lotfi.N., Eur.Phys.Soc.9. Trends in Physics, Symp.10, liquid-Glass Transition ( Florence, 1993) T2.

[8]. Nakheli.A., Lotfi.N. et Huck. J., 1994 Adv. Mater. Res1-2 287-89

[9]. Lotfi.N., Nakheli.A., et Huck. J., 1994 Adv. Mater. Res1-2 296-8

[10]. DA SILVA et al, A Strain Gauge Tactile Sensor for Finger-Mounted Applications, VOL.51, NO. 1, FEBRUARY-2002

[11]. J.-L. Le Goer, J. Avril, Capteurs à jauge extensométrique, Techniques del'ingénieur, pp. 01, 2000

[12]. O. Kursua, A. Kruusingb, M. Pudasb, T. Rahkonen, Piezoelectric bimorph charge mode force sensor Timo Rahkonena, article science direct, 2009

[13]. A. Nakheli., A. Eljazouli., M. Elmorabit., E. Ballouki., J. Fornazero et J. Huck J. Phys. Condens. Matter 11 (1999) 7977-7994

[14]. CRC Handbook of Chemistry and Physics Tableau (Éthanol) Page D-236

[15]. WO2013105840 A1 Densimeter, PCT/MA2012/000015 Abdelrhani Nakheli \&Seddik Bri. 